\title{
Perceived support and psychological outcome following the 2004 tsunami: a mixed-methods study
}

\author{
Jonathan I. Bisson, ${ }^{1,2}$ Catrin Lewis, ${ }^{3}$ Michael Howlett, ${ }^{4}$ Daniela Corallo, ${ }^{5}$ Ellen Davies, ${ }^{2}$ \\ Vivien Norris ${ }^{6}$
}

The Psychiatrist (2011), 35, 283-288, doi: 10.1192/pb.bp.110.030403

\begin{abstract}
${ }^{1}$ Cardiff University School of Medicine; ${ }^{2}$ Cardiff and Vale University Health Board; ${ }^{3}$ Cardiff University; ${ }^{4}$ Zito Trust; ${ }^{5}$ National Audit Office; ${ }^{6}$ Powys Local Health Board

Correspondence to Jonathan I. Bisson (bissonji@cf.ac.uk)

First received 23 Mar 2010, final revision 11 Jan 2011, accepted 1 Mar 2011

Aims and method The effectiveness of official support provided following a disaster has not been fully evaluated. This study aimed to ascertain whether there was an association between perceived support shortly after the 2004 Indian Ocean tsunami and later mental health symptoms in those affected, and to explore the factors associated with this. A survey, semi-structured interviews and focus group were used to explore the experiences and perceptions of 116 individuals severely affected by the tsunami.

Results Agency or official support was perceived as poor overall. Perceived ineffectiveness of support available within a few days after the tsunami was associated with increased symptoms of post-traumatic stress disorder 15-19 months later. The strongest themes that emerged from our study were that support provided in a humane manner was perceived as effective and that uncoordinated support, poor communication and limited accessibility to support and information were perceived as ineffective.
\end{abstract}

Clinical implications Improved planning of coordinated, flexible, multi-agency responses to traumatic events before they occur is required.

Declaration of interest None.
Natural disasters affect individuals in various ways. The physical, social and psychological demands can be overwhelming and are often accompanied by loss of resources that impairs the ability of individuals and communities to function optimally and deal with the effects of them. ${ }^{1}$ Natural disasters can precipitate specific psychological sequelae, including post-traumatic stress disorder (PTSD), not only in those directly involved, but also in relatives and friends who become aware that a loved one is missing. ${ }^{2,3}$

Systematic reviews have demonstrated good evidence that perceived lack of social support is associated with the development of PTSD. ${ }^{4,5}$ This and the apparent ineffectiveness of routine structured psychological interventions, such as single-session individual psychological debriefing or trauma-focused cognitive-behavioural therapy (CBT) for everyone involved in traumatic events, ${ }^{6-8}$ has resulted in the recommendation that initial support is primarily practical and pragmatic, and delivered in a sympathetic manner by non-mental health professionals. ${ }^{8}$ Traumafocused CBT has been shown to be effective for individuals who develop severe early symptoms or symptoms that do not resolve over a period of weeks to months ${ }^{9,10}$ and should be reserved for such individuals.
Social support is difficult to define precisely but can be considered a significant resource for individuals and family members encountering stress. It has been argued that early and mid-term interventions should promote a sense of safety, calming, sense of self- and community efficacy, connectedness and hope. ${ }^{1}$ The Inter-Agency Standing Committee (IASC), formed by the heads of a broad range of United Nations (UN) and non-UN humanitarian organisations, produced guidelines on mental health and psychosocial support in emergency settings ${ }^{11}$ in which they described a pyramid of interventions based on the specific needs of individuals and communities. Everyone would receive varying levels of basic support and security, a smaller number would receive more specific community and family support, and a still smaller number would receive focused non-specialised support, with specialised services being mobilised for the minority who continue to have unmet needs. Official agencies have a major role in the provision of social support shortly after natural disasters. Previous studies have not, however, focused on the influence of this form of support on later traumatic stress symptoms. This is a mixed-methods study to describe the impact of support provided by official organisations in the aftermath of a disaster. 
On the morning of 26 December 2004 an undersea earthquake measuring 9.3 on the Richter scale occurred near the Indonesian island of Sumatra. The earthquake triggered a series of devastating tsunamis that spread throughout the Indian Ocean hitting the coasts of 13 neighbouring countries including parts of Thailand, Indonesia, Sri Lanka and India. As many as 230000 people lost their lives. Approximately 10000 British citizens were in the affected area at the time the tsunami struck. It is believed that 151 were killed and many others injured. Many more were affected indirectly by having had loved ones in one of the affected areas.

In 2005 the National Audit Office commissioned the Zito Trust to assess the views and experiences of support offered by government departments and agencies to UK citizens directly affected by the tsunami. The National Audit Office report was published in November 2006. ${ }^{12}$ This study aimed to ascertain whether there was an association between perceived support shortly after the tsunami and later mental health symptoms, and to explore the factors associated with positive and negative perceptions of social support. We hypothesised that there would be a relationship between perceived poor support and later mental health symptoms.

\section{Method}

A qualitative and quantitative approach to data gathering was adopted, with questionnaires, semi-structured interviews and a focus group. The study used a sequential explanatory design, whereby qualitative data were gathered to explore and explain the quantitative results.

\section{Participants}

We invited 290 people to take part in the study. The majority of these individuals attended a memorial service in London and were among the most severely affected by the tsunami. Of those contacted, 116 completed the survey (40\%); 66 were in the affected areas at the time of the tsunami $(57 \%)$ and 50 were in the UK or elsewhere in the world (43\%). The latter group was included on account of their traumatic experiences and extensive contact with UK agencies in the weeks and months after the tsunami. Many flew to the affected areas to search for loved ones, whereas others identified bodies from photographs on the internet or waited at home anxiously watching media coverage. Gathering their opinions was considered vital to generate a comprehensive view of the UK government's response. Participants' ages ranged from 18 to 75 and above; 63 were female (54\%) and 53 male (46\%). One-hundred and ten (95\%) described their ethnic origin as 'White British'. Sixtythree had lost a loved one in the tsunami (54\%). Ninetythree questionnaire respondents $(80 \%)$ agreed to be interviewed and the 29 who participated were chosen purposively from this sample to ensure a range of different experiences, various ages and that both males and females were included. The focus group comprised ten survivors and family members who were already participants.

\section{Measures}

A mixed-methods approach using the combination of quantitative and qualitative data was adopted, with survey questionnaires, semi-structured interviews and a focus group. The study used a sequential explanatory design, ${ }^{13}$ whereby qualitative data were gathered to explore and explain the quantitative result. Data collection was carried out between April and July 2006, i.e. 15-19 months after the tsunami.

\section{Survey}

A questionnaire (available from the authors on request) was developed with significant input from tsunami survivors to generate quantitative and qualitative information regarding experiences and perceptions of efficacy of support from various agencies during the first few days, the first 2 months and subsequently. It consisted of a combination of multiple choice questions, open-ended questions and 1-7 visual analogue scales where 1 indicated 'as ineffective as I can imagine', 4 'neither effective nor ineffective' and 7 'as effective as I can imagine'. Separate versions were developed to gather the views of those who were in the affected areas at the time of the tsunami and those who were in the UK or elsewhere in the world. Participants were also asked to complete the revised Impact of Event Scale (IES-R) ${ }^{14}$ and the Hospital Anxiety and Depression Scale (HADS), ${ }^{15}$ wellvalidated self-report measures to determine PTSD, anxiety and depression symptomatology.

\section{Semi-structured interviews}

Interviews were conducted throughout the UK by trained professionals and sought to elaborate on information gained through the written questionnaire.

\section{Focus group}

Preliminary findings were shared with a group of ten survivors and family members to ascertain whether emerging themes corresponded with their experiences. The focus group was facilitated by a consultant clinical psychologist (V.N.).

\section{Analysis}

A triangulation approach using the information gained from the survey, the semi-structured interviews and the focus group was adopted to ensure reliability. The quantitative data from the survey were analysed using SPSS software for Windows. Independent sample $t$-tests were used to examine hypothesised relationships between different groups of participants using the total IES-R score as the outcome variable. The qualitative data were analysed by two researchers using an interpretive phenomenological analysis approach and the software package NVivo 7 (www.qsrinternational.com) for Windows. Emerging themes were developed by reading and re-reading the verbatim data until a number of meaningful categories were created. Towards the end of the qualitative analysis process no new categories were created, suggesting that all major themes had been identified. 


\begin{tabular}{|c|c|c|c|c|c|c|}
\hline & \multicolumn{2}{|c|}{$\begin{array}{l}\text { First hours } \\
\text { and days }\end{array}$} & \multicolumn{2}{|c|}{$\begin{array}{c}\text { During the first } 2 \text { months } \\
\text { after return }\end{array}$} & \multicolumn{2}{|c|}{$\begin{array}{c}\text { From first } 2 \text { months } \\
\text { to present }\end{array}$} \\
\hline & $n^{\mathrm{b}}$ & $\begin{array}{l}\text { Mean score } \\
\text { (s.d.) }\end{array}$ & $n^{\mathrm{b}}$ & $\begin{array}{l}\text { Mean score } \\
\quad(\text { s.d. })\end{array}$ & $n^{\mathrm{b}}$ & $\begin{array}{c}\text { Mean score } \\
\text { (s.d.) }\end{array}$ \\
\hline \multicolumn{7}{|l|}{ Average scores on effectiveness of different agencies } \\
\hline Tourists & 37 & $5.7(1.5)$ & * & * & * & * \\
\hline Local people/services & 57 & $5.6(1.5)$ & * & * & * & * \\
\hline People travelling with my loved ones & 21 & $5.0(2.2)$ & * & * & * & * \\
\hline Friends/contacts in other areas & 27 & $5.0(2.5)$ & * & * & * & * \\
\hline UK emergency telephone line & 48 & $2.4(1.9)$ & * & * & * & * \\
\hline Non-UK agencies & 37 & $4.0(2.2)$ & * & * & * & * \\
\hline Unknown officials & 20 & $2.6(2.5)$ & * & * & * & * \\
\hline Red Cross & 38 & $3.1(2.2)$ & * & * & * & * \\
\hline Embassy/consul of the relevant country & 32 & $3.1(2.1)$ & * & * & * & * \\
\hline FCO/UK embassy & 77 & $2.7(2.0)$ & 51 & $3.5(2.1)$ & * & * \\
\hline Police family liaison officers & 22 & $2.4(2.1)$ & 68 & $4.9(2.1)$ & 56 & $5.1(2.1)$ \\
\hline Tsunami Support Network via the Red Cross and FCO & * & * & 56 & $5.1(2.1)$ & 66 & $5.6(1.7)$ \\
\hline Local GP & * & * & 65 & $4.8(2.2)$ & 50 & $4.9(2.0)$ \\
\hline Police & * & * & 54 & $4.8(2.1)$ & 42 & $5.0(2.1)$ \\
\hline Privately funded counselling/therapy & * & * & 28 & $4.6(2.1)$ & 25 & $4.7(2.1)$ \\
\hline Local hospitals - physical care & * & * & 27 & $4.4(2.3)$ & 21 & $4.1(2.6)$ \\
\hline FCO assistance package & * & * & 36 & $4.2(2.5)$ & 44 & $4.8(2.3)$ \\
\hline Experience of how well agencies worked together & 30 & $2.8(2.0)$ & 54 & $3.5(2.1)$ & 52 & $3.7(2.2)$ \\
\hline Department for Work and Pensions & * & * & 14 & $3.1(2.4)$ & 19 & $3.9(2.5)$ \\
\hline NHS-funded counselling/therapy & * & * & 38 & $3.0(2.1)$ & 28 & $3.8(2.3)$ \\
\hline Voluntary agencies & * & * & 17 & $2.5(2.0)$ & 24 & $3.7(2.6)$ \\
\hline Local Social Services & * & * & 17 & $2.1(1.9)$ & 15 & $2.3(2.0)$ \\
\hline \multicolumn{7}{|l|}{ Memorial service organised by the Department for } \\
\hline Culture, Media and Sport & * & * & * & * & 64 & $5.2(2.2)$ \\
\hline FCO assistance to return for anniversary & * & * & * & * & 41 & $4.4(2.7)$ \\
\hline
\end{tabular}

FCO, Foreign and Commonwealth Office; GP, general practitioner; NHS, National Health Service.

a. The rating of effectiveness was on a scale from 1 to 7 , where 1 was 'as ineffective as I can imagine', 4 was 'neither effective nor ineffective' and 7 was 'as effective as I can imagine'.

b. Number reporting contact with specific agency.

${ }^{\star}$ Question not asked.

\section{Results}

\section{Quantitative data}

Perceived effectiveness of support

People's experiences of official/agency support following the tsunami were extremely variable. Table 1 shows the perceived levels of effectiveness of various people/agencies using mean scores from the 1-7 visual analogue scales.

Immediate aftermath Overall, individuals felt that the level of agency support was ineffective in the minutes and hours after the tsunami (mean $=3.0$, s.d. $=1.8, n=60)$ and a few days afterwards (mean $=3.7$, s.d. $=2.0, n=51$ ). In the first hours and days, local people/services and fellow travellers were perceived as providing the most effective support. There was no expectation of significant external help until day 2-3 but even after this time no UK agency was perceived as providing effective support.

The weeks and months after the tsunami The assistance that was felt to be most effective in the following weeks and months was from the Tsunami Support Network (TSN), police family liaison officers and general practitioners (GPs). The memorial service was also very well received. Assistance provided by voluntary agencies, Social Services and National Health Service (NHS)-funded counsellors/therapists was rated least effective.

\section{Symptoms reported}

The scores on the questionnaires indicated relatively high levels of reported symptomatology 15-19 months after the tsunami. Forty-two individuals (37\%) scored above 33 on the IES-R, a cut-off found to predict the presence of PTSD. The mean score on the IES-R was 25.3 (s.d.=19.1). Fiftythree individuals $(46 \%)$ scored above 10 on the HADSanxiety, a cut-off found to predict the presence of clinically significant anxiety. The mean score on the HADS-anxiety was 9.8 (s.d.=3.3). Twenty-three individuals $(20 \%)$ scored above 10 on the HADS-depression, a cut-off found to predict the presence of clinically significant depression. The mean score on the HADS-depression was 9.2 (s.d. = 2.3).

There were no significant differences between the IES-R results of those in the affected regions or those in the UK or elsewhere at the time of the tsunami, or between males and females. Those respondents who lost family, friends or relatives to the tsunami scored significantly higher on the IES-R than those who did not lose any loved ones (mean difference $=8.86$, 95\% CI 1.99-15.73). There were no significant differences between participants in the affected areas who rated the overall support in the first minutes and hours after the tsunami as ineffective $(<4)$ and those who rated it effective $(>4)$. However, those who rated the overall support ineffective in the first few days after the tsunami scored significantly higher on the IES-R than those who rated it effective (mean difference $=14.26,95 \%$ CI 
Box 1 Key qualitative themes that emerged after analysing the study data

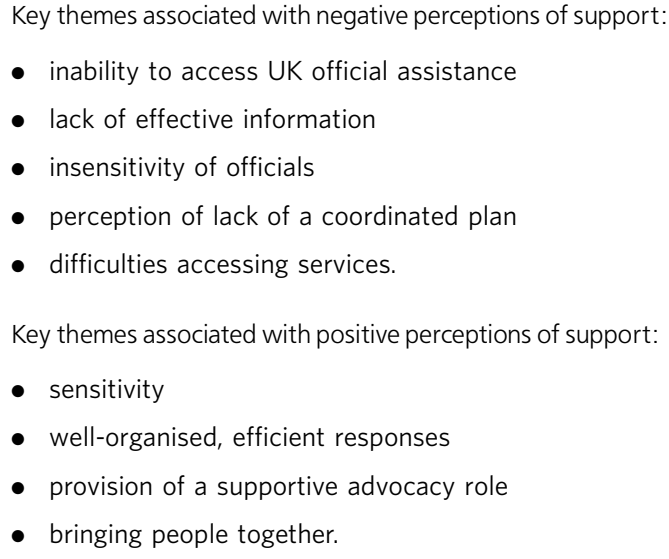

4.13-24.4). This result links to the distinction between the first 24-48 hours when external assistance was not expected and after 2 or 3 days when it was.

\section{Qualitative data}

Emergent themes are presented in Box 1 and discussed below, with reference to associations with negative and positive perceptions of support.

Themes associated with negative perceptions of support

Inability to access UK official assistance Those in the affected areas did not expect an official UK presence in the first 24-48 hours. After this time, perceived lack of support led to feelings of isolation, frustration and abandonment.

'I believed that your government, with all its immense resources, after about 24-48 hours, would be there in some force to help you. And I found that wasn't so.'

Lack of information There did not appear to be a clear system in place for gathering or disseminating information. This was perceived as a fundamental need that was not met.

'If there had been a telephone number to call who could have answered questions or at least updated us on search activities. As it was, there was absolutely no support.'

Insensitivity of officials Respondents reported encounters with officials who appeared to lack empathy and understanding.

'The British embassy didn't have a clue. They had no emotional connection, no attempt to say "Are you ok?",

Perception of lack of a coordinated plan Respondents described a response which lacked organisation and coordination.

'There was no equipment there, no computers. I don't think they even had a telephone to be honest.'

In the longer term, individuals were often unaware of available services. Legislation aimed at data protection prevented the sharing of information between departments.
'So I think it would have been useful for departments to share information much more efficiently than they did.'

Bureaucracy and difficulties accessing services One of the most prevalent difficulties after returning to the UK was accessing support.

'I wasn't trying to screw the system, but it was a nightmare you know ... they should have a record of me being there.'

Difficulties accessing psychological support through the NHS were also reported.

Themes associated with positive perceptions of support

Sensitivity The strongest theme concerned the power of humanity - help given when required, with sensitivity, was deeply comforting.

'The embassy staff when we got to Bangkok were wonderful. She sat and cried with me.'

Well-organised efficient responses Some individuals reported receiving a well-organised, efficient response to their practical needs. This was appreciated.

'But I do remember thinking we have been very well processed through their system.'

Provision of a supportive advocacy role Services that provided a supportive advocacy role were highly valued. This included family liaison officers, GPs and British Red Cross personnel.

'The Red Cross have helped us gain information on the inquest, memorial services and psychological support package.'

Bringing people together On return to the UK, people valued enormously the opportunity to meet others, share experiences and spend time together.

'I think what helped... was the fact that other people would be there who were similarly affected.'

\section{Discussion}

Participants perceived the official support received in the aftermath of the tsunami as poor overall. There was a strong relationship between perceived ineffectiveness of support within a few days of the tsunami and symptoms of PTSD 15-19 months later. This relationship was not present for perceived support in the first minutes and hours at which point there was no expectation of assistance, suggesting that it is only when assistance is expected but not received that there is an impact on later PTSD symptoms. The strongest themes were that support provided in a humane manner was perceived as effective and that uncoordinated support, poor communication and limited accessibility to support and information were perceived as ineffective.

\section{Strengths and weaknesses of the study}

This is the first study of psychosocial disaster response to use a robust qualitative method with a combination of data collection methods. Two researchers independently went backwards and forwards between the raw data and the process of conceptualisation to make sense of the data. ${ }^{16}$ The emerging themes were tested for validity using 
recognised techniques, ${ }^{17}$ including regular discussion of emerging themes by the research team; triangulation to compare the results from different sources; review of the emerging themes in a focus group and deviant case analysis; and the use of quantitative evidence to test the conclusions where appropriate.

The sampling strategy was theoretically comprehensive and saturation of themes appeared to be achieved, but the study was not designed to determine the views of everyone affected by the tsunami. Indeed, the focus was on those most affected by it. Only $40 \%$ of those contacted took part, which may have introduced bias to the results, although we have no evidence for or against this. The number of people invited to participate was limited by the lack of a comprehensive list of those affected by the tsunami and Data Protection Act issues. They may not have been representative of typical individuals affected and we suspect are likely to be at the more affected end of what is likely to be a spectrum of experiences. As a result, caution should be exercised in terms of the generalisability of the results to everyone affected by the tsunami or by other natural disasters.

The quantitative measures employed were designed to measure symptoms of PTSD, anxiety and depression but other issues may have contributed to the scores, including grief. It is possible that perceptions of helpfulness are shaped by the degree of response and therefore do not truly reflect how appropriate the level of support actually was. It is also possible that particular individuals are predisposed to viewing events in particular ways. The fact that the significant difference emerged at the time when it was reasonable to expect help, and not at all time periods, does not support this, but without characterising participants before they were exposed to the traumatic experience this is impossible to fully address. The results were limited to the perception of support as it was not possible for any objective measurement of service provision to be made. It is, however, possible that higher-quality services would have been associated with better outcomes.

Finally, it is important to note that data collection occurred 15-19 months after the tsunami. This introduces the issue of reliability of memories of traumatic events and the possibility of recall bias. Recent research has suggested that individuals who experience more symptoms may be prone to increased reporting of precipitating traumatic events over time. ${ }^{18}$

\section{Clinical implications}

The results of this study should inform improved planning of coordinated, flexible, multi-agency responses to traumatic events before they occur in line with previously published guidelines. ${ }^{8,11}$ Psychosocial components should be fully integrated with other aspects of the plan. The association between perceived ineffective support and PTSD symptoms is consistent with previous research ${ }^{4,5}$ and underlines the fact that an inadequate response magnifies the psychological risks consequent upon involvement in a traumatic event. The finding that humanity was appreciated even when there was little that could be done suggests the need for a basic level of training in effective communication for all providers of assistance following traumatic events.

This study has major implications for many organisations including emergency services, government departments, Social Services, voluntary bodies, non-governmental organisations and health providers, whose staff often have early contact with traumatised people. The limited perceived effectiveness of the psychological and emotional support provided by the UK's NHS is a major concern, particularly seeing that over a half of study participants described clinically significant levels of traumatic stress, depression or anxiety. This figure may well have been higher sooner after the tsunami, given the tendency for symptoms to improve over time. ${ }^{19}$ Some issues can be addressed more easily than others. For example, improving the communication skills of staff has been achieved in other areas. ${ }^{20}$ Other issues require more detailed planning and have greater resource implications, for example enhancing health services to meet the recommendations of the National Institute for Health and Clinical Excellence for PTSD. ${ }^{8}$

\section{Future research}

There remain unanswered questions including exactly what should be provided, when and by whom following a disaster. It is hoped that new approaches will be developed and properly evaluated incorporating the lessons that have already been learnt. This will avoid the now all too familiar sight of officials apologising for an inadequate response. ${ }^{21}$ As one participant said, 'No help is better than bad help'.

\section{Funding}

The study was funded by the National Audit Office.

\section{Acknowledgements}

The Zito Trust was commissioned to gather the views of victims and their families who needed these services.

\section{About the authors}

Jonathan I. Bisson, director of research and development, Cardiff University School of Medicine and Cardiff and Vale University Health Board, Catrin Lewis, PhD student, Cardiff University, Michael Howlett, mental health consultant, former director, Zito Trust, Hay-on-Wye, Daniela Corallo statistician, National Audit Office, Bromley, Kent, Ellen Davies, consultant clinical psychologist, Cardiff and Vale University Health Board, Vivien Norris, consultant clinical psychologist, Powys Local Health Board, Wales.

\section{References}

1 Hobfoll SE, Watson P, Bell CC, Bryant RA, Brymer MJ, Friedman MJ, et al. Five essential elements of immediate and mid-term trauma intervention: empirical evidence. Psychiatry 2007; 70: 283-315.

2 American Psychiatric Association. Diagnostic and Statistical Manual of Mental Disorders (4th edition) (DSM-IV). APA, 1994.

3 Galea S, Nandi A, Vlahov D. The epidemiology of post-traumatic stress disorder after disasters. Epidemiol Rev 2005; 27: 78-91.

4 Brewin CR, Andrews $B$, Valentine JD. Meta-analysis of risk factors for posttraumatic stress disorder in trauma-exposed adults. J Consult Clin Psychol 2000; 68: 748-66. 
5 Ozer EJ, Best SR, Lipsey TL, Weiss D. Predictors of posttraumatic stress disorder and symptoms in adults: a meta-analysis. Psychol Bull 2008; 129: $52-73$.

6 Rose S, Bisson J, Churchill R, Wessely S. Psychological Debriefing for Preventing Post Traumatic Stress Disorder (PTSD). Cochrane Library, Issue 1. Update Software, 2005.

7 van Emmerick A, Kamphuis J, Hulsbosch A, Emmelkamp D. Single session debriefing after psychological trauma: a meta-analysis. Lancet 2002; 360: 766-71.

8 National Collaborating Centre for Mental Health. Post-Traumatic Stress Disorder: The Management of PTSD in Adults and Children in Primary and Secondary Care. Gaskell, British Psychological Society, 2005.

9 Bryant RA, Sackville T, Dang ST, Moulds M, Guthrie R. Treating acute stress disorder: an evaluation of cognitive behavior therapy and counselling techniques. Am J Psychiatry 1999; 156: 1780-6.

10 Ehlers A, Clark DM, Hackmann A, McManus F, Fennell M, Herbert C, et al. A randomized controlled trial of cognitive therapy, a self-help booklet, and repeated assessments as early interventions for posttraumatic stress disorder. Arch Gen Psychiatry 2003; 60: 1024-31.

11 Inter-Agency Standing Committee. IASC Guidelines on Mental Health and Psychosocial Support in Emergency Settings. IASC, 2007.

12 The National Audit Office. Review of the Experiences of United Kingdom Nationals Affected by the Indian Ocean Tsunami. National Audit Office, 2006.
13 Creswell JW, Plano Clark VL. Designing and Conducting Mixed Methods Research. Sage, 2007.

14 Weiss DS, Marmer CR. The Impact of Event Scale - Revised. In Assessing Psychological Trauma and PTSD (eds JP Wilson, TM Keane): 399-411. Guilford Press, 1997.

15 Zigmond AS, Snaith RP. The hospital anxiety and depression scale. Acta Psychiatr Scand 1983; 67: 361-70.

16 Pope C, Mays N. Reaching the parts other methods cannot reach: an introduction to qualitative methods in health and health services research. BMJ 1995; 311: 42-5.

17 Mays N, Pope C. Assessing quality in qualitative research. BMJ 2000 320: $50-2$.

18 Engelhard IM, van den Hout MA, McNally RJ. Memory consistency for traumatic events in Dutch soldiers deployed to Iraq. Memory 2008; 16: 3-9.

19 Galea S, Vlahov D, Resnick H, Ahern J, Susser E, Gold H, et al. Trends of probable post-traumatic stress disorder in New York City after the September 11 terrorist attacks. Am J Epidemiol 2003; 158: 514-24.

20 Fallowfield $\mathrm{L}$, Jenkins $\mathrm{V}$, Farewell $\mathrm{V}$, Solis-Trapala I. Enduring impact of communication skills training: results of a 12-month follow-up. $\mathrm{Br} J$ Cancer 2003; 89: 1445-9.

21 Brash W. Bush apologises for Katrina, and he should. Online Opinion 2005: 20 September (http://www.onlineopinion.com.au/view.asp? article $=32$ )

\title{
Polypharmacy and high-dose antipsychotics at the time of discharge from acute psychiatric wards
}

\author{
Tongeji E. Tungaraza, Uzma Zahid, Bhanumurthy Venkataramaiah ${ }^{1}$
}

The Psychiatrist (2011), 35, 288-292, doi: 10.1192/pb.bp.110.033167

${ }^{1}$ Wolverhampton City Primary Care Trust, Wolverhampton, UK

Correspondence to Tongeji E. Tungaraza (eliphaz@doctors.org.uk) First received 26 Oct 2010, final revision 16 Jan 2011, accepted 1 Mar 2011

\begin{abstract}
Aims and method To determine the extent of prescribed antipsychotic polypharmacy and high-dose antipsychotics at the time of discharge from an acute psychiatric ward. Copies of discharge summaries for patients between the ages of 18 and 65 were examined; only those that had antipsychotic medications at the time of discharge were included. Names and doses of antipsychotics and all other medications concurrently prescribed were recorded.
\end{abstract}

Results A total of 651 discharge summaries were included in the study. Nearly a quarter of individuals were discharged on one antipsychotic as the only medication to take home; only $6.8 \%$ were discharged on a high-dose antipsychotic and of those on combinations $59.6 \%$ were on depot medications. Combining antipsychotics significantly predicted the use of high dose.

Clinical implications Most patients were discharged on doses of antipsychotics within the British National Formulary limits; however, a small proportion is still sent home on high doses of antipsychotics. Combining antipsychotics remains the strongest predictor of high-dose antipsychotic use; clinicians need to be aware of this.

Declaration of interest T.T. has received speaker's fees from Bristol-Myers-Squibb. He has accepted honoraria from a number of pharmaceutical companies. No funding was solicited for this study.
Antipsychotic polypharmacy and the use of higher than the recommended doses of antipsychotics continue to be practised in psychiatry. ${ }^{1,2}$ A nationwide audit in the UK involving 32 mental health services revealed that $34-36 \%$ of in-patients were prescribed high-dose antipsychotic medications and 39$46 \%$ were on antipsychotic polypharmacy 1 year apart. ${ }^{3}$

Polypharmacy and high-dose antipsychotic use has been associated with a number of unfavourable outcomes 